\title{
Interview with Sir Aubrey Lewis by Dr D. L. Davies (1967)
}

This is the second of two interviews with SIr Aubrey Lowis at the time of his retirement. The first interviow by Professor Michoel Shepherd in 1966 was publithed in the Psychiaticic Bullotin in 1993 (17, 738-747).

I suppose the two most important events during the war years were the report of the Goodenough Committee and the building up of the new system of the NHS which would involve a complete change in the status of the Maudsley Hospital?

I think a third might be the regular recognition that psychiatry must occupy a larger place in the whole of the medical service than it had hitherto. For example, a committee was created to advise the government on the organisation of psychiatry within the armed services. The committee had predominately civilian membership: Henderson and I were the two psychiatrists on it, Sir Wilson Jameson was the chairman and it did, in a quiet way, influence a good deal the steps that were taken during the war to put psychiatry on a fairly solid foundation, in the armed services anyhow, and consequently, of course, in the Emergency Medical Service (EMS), and so by extension in the whole of the health service.

But you are right, the Goodenough Committee did play a very large part in the developments during the war and fortunately the vicechairman was Sir John Stopford. When I had to give evidence before them, he was in the chair and was clearly aware of the difficulties in putting psychiatry on a proper footing within the health service as a whole. During my appearance before them it was a little difficult because there was an air-raid at the time. The bombs kept falling all round us and every question or answer was punctuated by this noise, but I had the general impression that they were aware of the need to put psychiatry on a much more broad and firm foundation than had been the case hitherto. The secretary, Farrer-Brown, who subsequently became secretary of the Nuffield Foundation, discussed with me the memoranda I had submitted and the evidence I had given orally. On the strength of that the Goodenough Committee report did, as you know, suggest that the Maudsley, and perhaps Edinburgh, should be the two centres of excellence which would provide a guide, or at least an impetus and perhaps even a model, for the development of psychiatric training centres in addition to those that provided ordinary clinical services.

The implementation of the Goodenough Committee recommendations wasn't very easy because the London County Council (LCC), which had to play a large part in it, was not ready to spend a great deal of money on teaching and research. It devolved on the individual organisations to make hay while the sun shone, and we were able to do that with the LCC and the Rockefeller Foundation support in Switzerland in helping towards the continuance of the research programme and its extension.

There was a curious interim period during which the hospital was neither one thing nor the other. The LCC was doing its best to put the hospital on its feet, but it was clear that the LCC was going to hand over the reins to the National Health Service and the University of London was busy developing the British Postgraduate Medical Federation, in which the Institute of Psychiatry was to be a part. It was pretty widely recognised that by the terms of the Goodenough Committee we had to be a very important integral section of the federation, and even an independent school of the university. That position was held only, I think, by the London School of Hygiene and Tropical Medicine and perhaps the Lister Institute and we were surrendering that status in order to gain the greater advantages of incorporation within the federation. Many people were uneasy because they thought that losing direct access to the university might mean losing access to the money which the university would have at its disposal, and if it all fell through without a committee of the federation they felt that other specialities would perhaps hardly recognise the needs of psychiatry. However, the risk was taken and of course in the event it was clear that we were not discriminated against. On the contrary, we received the maximum help from the federation in regard to the finances and many other things.

At what point did the possible merger between Bethlem and the Maudsley come onto the horizon?

At the point when the National Health Service was being developed and its teaching section was receiving particular attention. That's where we 
were concerned and the Bethlem people, on their side, were also concerned about what their status was to be. Having previously enjoyed the status for some considerable time of being the only important training centre, they were now faced with the prospect of becoming a backwater. Gerald Cook, who was called the Treasurer and the Chairman of the Bethlem Governors, asked me to come and see him. We had further meetings and he said that as far as he was concerned he thought it was proper that Bethlem should be included in the National Health Service rather than opt out as many other hospitals with similar endowments had done. He knew that the Maudsley had more or less taken the place which Bethlem had once occupied and having discussed it with me on a number of occasions, he was satisfied as to the right course to follow. He got in touch with Alan Daley and Sir Wilson Jameson, with both of whom I had, of course, discussed it, as soon as he made his approach to $m e$, and from then on it was only matters of detail that were in question because he was really something of an autocrat at Bethlem and what he wanted done was done. On our side, both the Ministry and the LCC were aware of the great advantages that would accrue from the fusion of the two hospitals. So it was brought about and as Gerald Cook put it, neatly but unkindly, it was a marriage of brains and money.

The details of the relationship between the two hospitals might have presented trouble, judging from the records of other hospitals in a similar position, where the staff of one was not of the same standing as the staff of the other and a resentful and spiteful animus developed. It wasn't so with us. Those few people who weren't entirely happy about forming part of the teaching hospital staff left; the other staff were incorporated quite comfortably. The basic principle. which they happily accepted, was that the hospital should be one and not two hospitals with separate staffs, thereby overcoming a lot of difficulties at one stroke. It applied to nurses, doctors and every kind of staff.

I drew up a document at the time which proposed using Bethlem for certain special services, for example for having a small section of chronic patients of whom we hadn't had any at the Maudsley, and various other things. The one that I chiefly concentrated on was the geriatric section which I felt we must have, and that encountered great opposition from the then Matron of Bethlem. I think she had a false notion of what was proposed. She foresaw a ward of purely old people not responding to treatment. Knowing the hot temperature and tempo of the place. I could see that it was against her opposition that something was done but we had Felix Post here already with an interest in this field and eventually Bethlem was given its geriatric unit. There were other possible developments at that time which I think would have been logical and tidy, but they couldn't very well be made because people were afraid it would relegate Bethlem to a secondary status.

I remember the document; I think in fact you had in mind to complement the Maudsley's activities in vartous directions and although this happened to some extent there was also a certain amount of duplication which I am not too sure you were very happy about.

No, I didn't see any sense in duplication because it would have meant more and more general wards of which we already had a fair supply, and insufficient specialisation along certain lines. However, what was eventually attained was a very happy compromise, I think. The adolescent unit was set up, and the gerlatric unit.

Before leaving the war-time perlod, would you say that it was just a question of marking time when you had to wait for the war to end, or in retrospect do you think that it was an essentially formattue pertod in the development of the hospital?

No, I don't think it was a formative period. Some people have said that it caused the psychiatrists of the Maudsley to turn their attention from psychoses, which had been their chief interest, to the neurotic conditions which were their chief concern during the war. I don't think that's true. As I recall the work that was going on here, I think there was as much interest in these neuroses which are so much more difficult in many ways than the psychoses to classify and examine. There was a great deal of work going on in that area and I don't think that we were so benighted and ignorant of the importance of the neurotic conditions and the problems they present. In consequence, I don't think that was an area in which the war contributed a great deal to the development of the Maudsley staff and their understanding of this large segment of psychiatry.

The people who were working the two hospitals, Sutton and Mill Hill, gained extra experience of a useful kind, but I wouldn't have regarded it as particularly formative. Indeed, it might be said to have been divisive in that the two hospitals came to have lives of their own and an ethos of their own and to attract loyalties to themselves which militated against the easy refusion of the two staffs when the time came to resume work here. Mill Hill, of course, went out of business, but Sutton continued and there was again a certain necessity for people to declare their allegiance one way or the other, so that I would say that the war was not a helpful or profitable period as it concerned the individual psychiatrists of the 
two hospitals. There was extra experience, but there were certain handicaps also involved.

When you came back to Maudsley from Mill Hill, I think that about that time you gave your presidential address to the Section of Psychiatry at the Royal Society of Medictine in 1946 on the education of psychiatrists. There had been six years between the death of Mapother and your official appointment. Is it accidental that your first major essay was on the education of psychiatrists?

No, I am sure it wasn't. It seemed to me to be important that no advances in psychiatry could be made unless there were psychiatrists with a broad understanding of the needs of the subject and of the opportunities that it offered. So I had no doubt that this was the theme on which I was most appropriately called on to talk.

The interval between Mapother's departure and my occupancy of the chair was, of course, the war period and the LCC wisely or unwisely decided against filling the chair until the war was over. That may also have been due to misgivings as to my fitness for the post since I was an obvious candidate. I wouldn't be in a position to know, but some other positions of the same kind that fell vacant were filled during the war and I think it was advantageous to the institution that they should have been filled. The war was a curious period and I am surprised when I look through the papers and see how active was the interest in planning and how sublime was the confidence we seemed to have that we would presently be back at work according to our desires. The importance of education has been foremost in the work of this hospital and in the medical school ever since the war. Of course it was so beforehand, but then it was less systematised and explicit than later on. The great influx of supernumerary registrars also underlined the importance of this side of the work.

When you came back here you found pretty well nothing, empty wards, I suppose, hardly any staff at that time and then, before the merger with Bethlem, not very much money. I suppose you set about butlding it all up?

It's curious that I seemed to have repressed most of this difficulty and trouble. I can't recall any problems of this kind that were urgent and insistent. I don't know where the nurses came from: some of them were brought back from Mill Hill and Sutton. Medical staff came back by degrees from the services, often promptly from the EMS. Indeed, many of the most urgent needs arose from the demobilisation of the medical staff and the people who came here as registrars. We had hurriedly to adapt ourselves to the demands of a vigorous school; I was concerned that we should not resume those six months cram courses which had been our main teaching activity before the war, and that we should institute now what has come to be known as the Academic Postgraduate Diploma syllabus, covering three years of systematic or organised training. There was opposition that I can remember now, but it took a little while, indeed quite a bit of battling, to get it through the university, because it meant jettisoning the existing DPM of the university which was slightly more difficult than the conjoint one but of the same sort, an external diploma. Nonetheless, that was achieved. I remember the Dean of the Faculty of Medicine at that time suggesting that there wouldn't be enough people taking this exam because these requirements for the preparation for it were so exacting. That didn't turn out to be the case.

As far as research was concerned, the Rockefeller money had been partly spent during the war on Professor Eysenck and others who were its beneficiaries, but other sources of research money came to light. The Medical Research Council (MRC) more or less discovered us; I don't think they had given us much before the war. The Rockefeller Foundation continued to be well disposed towards us, although I think that at that time Dr Alan Gregg, the very enlightened and progressive director of the psychiatric side of the Rockefeller Foundation's expenditure, was coming to think the Tavistock Clinic was a more lively place and that its future was being frustrated somewhat by our standing in its light. He asked me whether I couldn't do my best to see that the Tavistock Clinic received university recognition and I was in a somewhat awkward quandary for I didn't think the standard of their teaching at that time was quite the sort the university would wish to endorse. On the other hand, I had every desire to please Dr Gregg, partly because he was such a forthright and helpful man in every way and partly because of a personal liking for him plus, of course, his share in all the assistance we had had from Rockefeller in the past. So I think I steered a middle course.

The hospital's help with research was, I suppose, invaluable too?

The money that had accumulated at Bethlem came by degrees to contribute more and more to furtherance of research and was therefore a very great help.

\section{I think it began around 1950}

Yes, I should think about then. There were several people who had been engaged almost exclusively on research. Professor Eysenck obviously had been engaged in nothing but research. After Professor Nevin's resignation I think Professor Mcllwain came as Professor of Biochemistry and was consequently also engaged almost 
exclusively, if not exclusively, in research. Then Professor Meyer likewise, so that there were departments in which research was almost the only concern and they were fed financially from various sources. And, of course, there was still Dr Guttmann here when we came back from the war. He was a very potent stimulus towards research.

I suppose your position, in contrast with Mapother's, was very different. He'd been head of a much more unified clinical and research organisation. You were strictly only one of six professors eventually in the institute, and the hospital was technically a separate organisation which had been made up of the two other hospitals.

Yes, the medical school was really a figment before the war. We had this six months' course. That was about all that it amounted to, apart from the fact that we had two professors, one of whom, Mapother, was part-time and he had various other commitments. Furthermore, as the structure of the hospital was modelled on that of the mental hospitals, which the LCC understood very well, he was the medical superintendent with powers of life and death, so to speak, and everybody else was subordinate.

As the end of the period of peace neared and war was impending Mapother had drawn up a programme for reconstitution of the staff which he submitted to them for comments and approval, if they saw fit. There was a good deal of dissent on the part of the younger people about some of his proposals. Some of them wanted the old style medical superintendent organisation to be perpetuated, others wanted it to be jettisoned, thrown overboard completely. Of course, the war interrupted all that but when we came back it was clear that we then found an era of what is usually called democratic control in which nobody would have the same powers as the medical superintendent used to enjoy. Nobody would have wanted to enjoy the same powers because they put too much responsibility on the shoulders of one person, which ended in friction.

The reorganisation of the medical school shifted the emphasis considerably away from the hospital in some respects and on to the medical school which became a much more lively affair than it had been previously. I don't mean to imply that the hospital became weaker in any sense, but whereas the hospital had borne the whole weight of teaching and research as well as clinical services before the war, it was now distinct. Then we had the usual surfeit of committees which continued to be a feature in the landscape and is still so, I suppose, whereas before the war nobody attended any committees at all except the superintendent.
Some institutes had, as well as a professor in the main subject, a director. What were your feelings about that?

It was proposed that, as had been the case before the war, I should continue as clinical director. which gave me certain responsibilities for the clinical services all over the hospital, particularly insofar as they subserved teaching and research. In fact, the terms which the university laid down at that time delineated the responsibilities of a professor, indicated that he must be in charge of the teaching throughout the hospital, which of course meant access to the patients all over the hospital.

The proposal to have me continue as clinical director after I was professor would have meant a very great deal more work for me obviously, and would have required even more tact than I possessed at that time I'm sure, in order to avoid friction with my colleagues. However, it was a proposal that had many advantages and would have brought the hospital into line with what has long been customary in some American universities, where there is teaching at university medical schools and university hospitals, and with what is at present now being practised in Oxford and elsewhere, where the chairman of the department has responsibilities of the directorial kind. We have seen something of the sort here in the Neurosurgical Unit where Murray Faulkner is Director. Hedley Atkins was Director of Surgery at Guy's Hospital before he was appointed to his chair. Seddon has been director of studies at the Orthopaedic Institute. However, as far as this place was concerned it was the subject of a right royal row. I was on holiday when the crucial meetings were held and I didn't feel so deeply involved on one side or the other that I wanted to come and join in the battle. Much rhetoric was deployed, I believe, and noble sentiments were uttered by all concerned. It was decided they didn't want a clinical director so that I was able to concentrate my interests in the hospital on the professorial unit of 80 beds, which is, after all, the size of many notable German clinics run by famous professors, so that I didn't take it deeply to heart or regard it as a major calamity for the hospital. I think they would have gained some advantages if they had had a clinical director. There would have been a good deal more unity in some ways, but there are also disadvantages which could have accrued.

Apart from the question of clinical directorship in the hospttal there is also the point that you were technically only one among six professors in the Institute. I think this is a point which always worrled the late Sir Francis Fraser when he was at the helm of the Federation. 
I was never worried about it because my colleagues were so generously disposed and so friendly and aware of the necessary predominance of psychiatry in a psychiatric institute that I was never conscious of any struggle against the other heads of departments. You yourself have looked on the scene for a long time. Did you notice any struggles of this kind? I can't recall them.

No, I think that it worked very well by a gentleman's agreement. I think that all the department heads had accepted the view that you were primus inter pares when it came to an issue as between psychiatry and other departments. My recollection is that in the last resort they always said it was an Institute of Psychiatry and psychiatry should take precedence.

Yes, I agree. I doubt if any purpose would have been served by insisting on the directorship.

No, I think on reflection that it might have been regarded as a restraint which it would never really have become but would have been felt as such.

Yes.

So would have been perhaps resented?

Yes.

The Goodenough report, I think, said that the Maudsley should become the European centre of progress in psychiatry?

That's the kind of claim which can't be substantiated. It's like the benefit of psychotherapy; you can have strong views about it, but it's very hard to stage a controlled experiment which would prove the point one way or the other. Whether the Maudsley became that or not is. I suppose, a thing on which many different opinions would be held. Certainly we attracted people from many different countries who came to work here and have been loud in their appreciation of what they found and what they got from their stay. In that sense, I suppose, it may be partly true. But it wouldn't be right to question me, I think, on this matter because I might be biased. I suppose that if one were absolutely honest about it one would say that no psychiatric institute in the world has quite the prestige that was one time attached to Kraepelin's Clinic in Munich or perhaps even to Adolf Meyer's department at Johns Hopkins, which were recognised all over the world as being the one important centre in their own country and as having great significance internationally. However, whether or not that could be applied to us, I would not be the right person to say.

Yet seeing those places now they look tiny and even insignificant.
I wouldn't say that quite, I doubt whether the Munich Institute is now what it was but I don't suppose it would be fair to describe Johns Hopkins as tiny.

The laboratorles remind me very much of the old rooms that we used to have here.

I think one has to reckon with the Immense expansion of psychiatric research in many centres. There's no one place now which is the obvious and sole repository of psychiatric enterprise and competence. No, I think even to compare the psychiatry of 1936 with the psychiatry of today is very difficult because there has been such an expansion of medical activity in every field. Certainly psychiatry has not been backward in putting forward its pretensions.

In view of all the different forces that existed here as you've described, how is it, do you think, that the term 'Maudsley psychiatry', which is used all over the world, has a particular connotation? Would you like to say what you think the connotation is and how it could have such a connotation with so many diverse elements.

The connotation is partly positive and partly negative. Taking the negative side first, it is not a place that is dominated by psychoanalytical or cognate speculations or theories. People recognise that and regard it therefore in a sense hard-headed, perhaps hypercritical, perhaps sceptical, but not pie in the sky or ethereal.

On the positive side. I should think that it is regarded as a centre where Maudsley psychiatry is concerned with empirical clinical methods strengthened by the results of research which enable theory to be formulated and eventually applied to practice. But I think it's chiefly in the balance that is observed in 'Maudsley psychiatry' which is regarded by many foreign countries as typical of the general English attitude in medicine, which is a balanced one, avoiding on the one hand the extremes of enthusiasm and bold claims, and on the other hand not settling down into a stagnant acceptance of things as they are. Whether it is right to regard these as English attributes or whether it is appropriate to apply them to the Maudsley, I don't know; I should think it probably is, so that when people, for example in America, are looking for a psychiatrist of a particular sort, they know what they won't get from here. They know that they are unlikely to get a man whose outlook is predominately psychodynamic. Should they find such a chap he won't be a typical product of the Maudsley; he would be a sport. If they want a man who is interested in social psychiatry or epidemiological psychiatry they know that there are quite a large number who now come from 
here and when they have to fill vacancies in American units they always turn to us and see if we have such people.

I think that the application of statistical methods to testing hypotheses is also accredited to us. Indeed, I have no doubt that there are many people not knowing the inner relationships of the staff who would regard Professor Eysenck as a typical Maudsley psychiatrist. It's often amusing to find that people think that he is a doctor and a psychiatrist and that his views are those held by the whole of the staff here. The late Professor Hargreaves used to be annoyed when I would say to him that people at the Tavistock Clinic said such and such, and he explained to me that the Tavistock had a great diversity of opinions and people. In the same way, I suppose, it's true that to the outside world we seem like a monolithic structure of sceptics and cautious observers and practitioners, while we know ourselves to be much less monolithic.

In some sense, I suppose, you've seen the development of social psychiatry as a way out of the dilemma of the organic and the dynamic approaches. Would it be true to say that?

I wouldn't have said it was a dilemma. I think that there is a proper place for the dynamic and the organic approaches very clearly, but the social side of psychiatry is so obtrusive at every point and has been in the history of psychiatry at all times, that I don't see how it has come to be neglected as it has, except that the methods of investigation are ill-formed and the whole subject of sociology is still embryonic. If it weren't for that I think the crying need for better knowledge of the social aspects of psychiatry would have been fully recognised. Whether you speak from the standpoint of the law or from the standpoint of, say, drug taking, drug addiction or the conditions within which certain forms of mental disorder appeared to be generated or fermented, you can see the social significance, the social considerations staring you in the face.

My own concern was given a fillip at the time of unemployment after the setback in 1930 or thereabouts, when there were a lot of unemployed people. With the help of Miss Galloway I made a study of their psychiatric condition. Letitia Fairfield, who was then at the LCC, gave us a list of people who were to be examined. I was one of a small committee that I think was made up by an investigating team of Desmond Curran and W. H. Gillespie and somebody else. The subjects were considered to be the hard nuts who couldn't be cracked, the core of unemployability, but, as soon as conditions improved, back they went to work. So that was certainly a line of social enquiry which has become more and more the concern of the Medical Research
Council Social Psychiatry Unit and other groups here.

It's impossible to draw a sharp line between the social and the epidemiological, or between the social and the psychological, I think. Often when I suggested to Professor Eysenck that there was a need for a social research worker here he would put the view that the psychologist was quite capable of carrying out any of the social psychological inquiries that were needed. These were, he claimed, much the same as sociological inquiries and when you look at the blurred outlines of the behavioural sciences of psychology, sociology, anthropology, you can see that a case can be made for the right of any of the people combing from any of these disciplines to attack problems which I suppose broadly can be seen as social problems.

Would you have liked, had it been possible, to have a separate department of sociology?

If there had been the right man. I think that's been the trouble, just as in the universities which have blossomed and burgeoned since the war. They have aimed at having a department of sociology but have found it very difficult to fill the chairs and more senior positions. It seems to me crucial that there's no point in having a chair if you haven't got the right man to fill it. There were times when it looked as if there might be somebody who would be the right person but then it proved impossible to attract him because more attractive posts were available elsewhere. And, of course, sociology is itself divided. You can have a professor of sociology like David Glass, who is a demographer, and you have others who are more interested in what are really psychological problems.

Looking back, what would you have wished different?

I am afraid that is a question that I would have to spend much more time thinking about. Its sounds as though I am a very contented man. doesn't it? Do you mean in the structure of the place, what alterations should there have been in the way things have developed?

Yes, at one time there was some doubt as how to proceed because conditions weren't by any means ideal either in the Institute or the hospital. There was perhaps a division of opinion as to whether one should rehouse the Institute first rather than the hospital or vice versa. In effect, it looks as if the Institute to some extent is being rehoused before the Maudsley. Do you think this was the right order?

Certainly, I have no doubt whatever. The institute came back to dispersed bulldings located on a larger site without any right of ownership or 
opportunities for fusing the activities of the various members of the institute and departments into one conglomerate co-ordinated body. The 111 effects of this situation are still, I think, apparent. People don't see enough of each other. It's possible to be around the place for three months and not see Professor Eysenck, simply because he works in his own way and doesn't dine in the same place as other people. Things of that sort do not apply only to Professor Eysenck but, generally speaking, they would have been, I think, obviated if the Institute had much earlier had its own house. So there would be no doubt whatever in my mind that it's the right priority, for which the hospital was adequately but not ideally housed. The Institute wasn't housed at all, it was living in ramshackle nomad accommodation, making the best of a bad job over a long period.

Another point is that in the development of the Federation as a whole, there's been the emphasis hitherto on the development of separate Institute/ Hospital complexes. Do you think that on the whole it would have been better for our own development that we should have been so separate?

Yes, it was better. One has to consider the time at which the particular development was occurring. At the time when it was first mooted that we should have a closer connection with a teaching undergraduate hospital, it would, I think, have been greatly to our disadvantage to have done so. Resources are not always adequate for all the needs of a large institution and we would have suffered, we would have been unable to do a lot of things we have been able to do because we would have had to obtain the approval of colleagues in other hospitals who had diverse aims and different needs from ours. Now I think we have reached the point where we can get along pretty well by ourselves, stand on our own feet in competition with the medical school over at King's College Hospital or for that matter at Guy's, and we gain by the association with them. I think that as King's, for example, observes more and more its academic departments which have lagged rather, as everybody knows, until the last few years, there is a mutual advantage for us to be on the friendliest and most intimate terms. We can call upon their services and collaborate with them, provided, of course, that our independence in certain areas is recognised. For example, this would arise in respect of the St Francis unit which we are so familiar with. I think it would be calamitous if because of the administrative changes that have been effected lately we were to lose the sole responsibility, or practically sole responsibility, for the investigation of patients there and powers of selecting from them those who might be admitted here. It has been an indispensable part of our total organisation. There are some other relationships of a similar kind, not with teaching hospitals but with mental hospitals, which required very close scrutiny and incessant vigilance. The trend of the times makes it unavoidable that we should collaborate with them in a much closer way than was necessary or, I think, desirable earlier on when they could have got in our path to a much more serious degree than they possibly could now. I suppose I am speaking very much from the standpoint of this hospital. I ought to be remembering the advantages to those other hospitals, which also have to be taken into account. King's gained by its association with us, Cane Hill gains by its association with us so that there is a mutual benefit which, it seems to me, isn't always fully recognised on the other side. They often think they are conferring benefits on us, but I think it's a reciprocal matter.

To some extent anyway, our natural links would be as much with local authorities as with other teaching hospitals.

Yes. However, I think that pressure from the University Committee at the university will enforce a closer link with the undergraduate teaching hospital over the road than has been the case hitherto. And King's is changing its character so fast and for the better that I don't think we need deplore this pressure if it comes. We can even anticipate it in some ways, although we must always be on our guard against invasion of our proper area of control.

Then you see a district commitment as something which can very well be assimilated to a teaching and research role?

Not easily. I think it's going to require a lot of hard work and thought and adjustment as time goes on. I think it's very difficult, and I wouldn't feel unrelievedly optimistic about the success of this venture, but it's got to be tried. It's in conformity with the spirit of the time and has much to recommend it if one sees psychiatry as a subject in which the epidemiological and social issues are quite prominent now. But unless psychiatry changes its character it could easily be the case that practitioners refer patients to other hospitals, even though they live in the area that we regard as our community, and we might find ourselves high and dry if we become unpopular or don't seem to give the same service as others. It's very hard to evaluate the merits and success of a service in psychiatry. I should think it's one of the most difficult problems that confronts the hospital as distinct from the medical school. However, in a document that I think is now published the University Grants Committee refers explicitly to the excellent relationship 
between the Maudsley and King's as a model for what should be the case from postgraduate institutes. There is no doubt at all that the climate in which we are now related to King's is very different from what it was when the neurosurgical unit was being formed. A degree of harmony is evidently the requisite for success in such a relationship.

You have referred of course to the fact that as we are now sufficiently mature to be independent, we can collaborate on a firmer footing with other people.

Yes. We have rather tended to hide our light under a bushel in some ways and it's been very difficult to assert ourselves sometimes in the way we should. The absence of any representative of this place on the regional board was a case in point wasn't it?

Within our own organisation here do you think that with so many developing sub-spectalittes psychiatry becomes a rather nebulous concept? General psychiatry becomes, in fact, a minority subject.

This is very unfortunate indeed; I am often quoted as having said that our business was to train the all-round psychiatrist and I still think that the psychiatrist who hasn't had an all-round training in his subject is as bad a psychiatrist as the doctor who hasn't had an all-round training as an undergraduate student in medicine is a bad doctor. I don't, therefore, regard the development of sub-specialities as likely to have these unfortunate consequences. I would regard it as very unfortunate if the general psychiatrist. the all-round psychiatrist, faded from the scene to be replaced by the expert in geriatrics, the expert in adolescence, the expert in alcoholism and so on. That would be as unfortunate as the disappearance of the general physician.

It is true that if you look at the professors of medicine at various universities and medical schools, you see that each of them has specialised in some area, the kidney or the heart or something or other, but they are also good general physicians and I think that's why they respect men like Rosenheim or McMichael. It's respect for the general physician and by analogy I should say that it would be calamitous in psychiatry if we had the extremes of specialis- ation taking place. That's why, for example, I couldn't see eye to eye with Dr Winnicott on the question of child psychiatrists. He holds that the people who can best treat children needing psychiatric attention are paediatricians who have been psychoanalysed. There could hardly be a more blatant denial of the value of a general psychiatric training.

But isn't it also the view in the United States that a psychiatrist is a general physician who has had an analysis and then is able to practise psychiatry?

Yes, but I wouldn't have much sympathy with that view. I think we see some of its ill effects if we look round.

I think you were once asked to write an article on the future of psychiatry, to look ahead, and I remember you telling me how difficult you thought it was.

I was asked to look ahead to 1984 , which was an unhappily chosen year perhaps. I did my best and, of course, it was speculative in the consequence, in the bad sense of the word, since these speculations couldn't be put to the test, at any rate by me. I would think that any confident prediction of the lines on which psychiatry is going to develop is quite out of the question. If you look at the recent history of psychiatry over the last 30 years, changes have appeared that nobody I think would have predicted in 1912 or 1920. I don't doubt that certain areas of psychiatry, particularly the social areas, will have been furthered a great deal by that time. And, I should think that psycho-analysis will have settled down into a more modest frame of mind on the part of its practitioners who will have recognised that uniess they can support their contention by evidence of a kind that is customary in scientific work, there will still be many sceptics and the standing of their work will recede. I suppose that by then people will have come to regard some of the forms of psychiatric or psychotherapeutic practice, and of psychopathology, as extravagant, whereas now they listen with respect to almost any views that are put forward. Further, these views are listened to with respect by a large section of the general public. 